\title{
Intrahepatic Bile Duct Cancer TNM Finding v7
}

National Cancer Institute

\section{Source}

National Cancer Institute. Intrahepatic Bile Duct Cancer TNM Finding v7. NCI Thesaurus.

Code C90182.

A finding about one or more characteristics of intrahepatic bile duct cancer, following the rules of the TNM AJCC v7 classification system. This is a novel staging system and applies only to intrahepatic cholangiocarcinomas and the rare combined hepatocellular and cholangiocarcinomas. Pure hepatocellular carcinomas are not included in this classification. (from AJCC 7th Ed.) 